\title{
APLIKASI REKAPITULASI KUESIONER HASIL PROSES BELAJAR MENGAJAR PADA STMIK INDONESIA BANJARMASIN MENGGUNAKAN JAVA
}

\author{
Muhammad Saidi Rahman, S.Kom, M.Kom. \\ (m.saidi.rahman@gmail.com)
}

\begin{abstract}
ABSTRAK
Kuesioner adalah metode pengumpulan data yang dilakukan dengan cara memberi seperangkat pertanyaan atau pernyataan tertulis kepada responden. Di STMIK Indonesia Banjarmasin kuesioner digunakan untuk memberikan penilaian terhadap kualitas dosen dan fasilitas ruang proses belajar mengajar agar nantinya dapat membantu meningkatkan kualitas akademik. Perhitungan atau rekapitulasi kuesioner di STMIK Indonesia Banjarmasin masih menggunakan program Microsoft Excel, sehingga untuk membuat laporan kuesioner masih memerlukan waktu dan masih kurang efektif. Program yang digunakan adalah Java 2 Standard Edition, dengan kompiler IDE Netbeans, dan untuk membuat laporan menggunakan iReport yang dibangun menggunakan library JasperReport. Perhitungan kuesionernya yang digunakan untuk merekapitulasi adalah perhitungan Skala Likert. Dengan adanya aplikasi Rekapitulasi Kuesioner Proses Belajar Mengajar ini bisa digunakan untuk mengurangi masalah dalam perhitungan rekapitulasi kuesioner proses belajar mengajar dan pembuatan laporan. Sehingga diharapkan akan mempermudah pihak yang terkait dalam proses perhitungan rekapitulasi kuesioner dan dapat pula membuat laporan secara mudah cepat dan akurat.
\end{abstract}

Kata Kunci : Kuesioner, Skala Likert, IDE Netbeans, Java, JasperReport, iReport

\section{PENDAHULUAN}

Kualitas dan kuantitas sangat penting dalam sebuah akademi untuk menjadikan para mahasiswa/i menjadi lebih berkualitas yang bisa diterapkan baik itu masih dalam masa kuliah atau setelah lulus nantinya. Untuk membangun itu semua tentunya tidaklah mudah bahkan memerlukan waktu yang cukup lama dan harus sejalan dengan visi dan misi akademi. Banyak sekali upaya yang bisa dilakukan untuk meningkatkan hal tersebut salah satunya melalui kuesioner yang berisikan masukan serta saran dari mahasiswa/i itu sendiri. Hal ini sangat diperlukan agar kedepannya sebuah akademi ini bisa menjadi lebih baik lagi dan untuk kepentingan bersama. Sebaliknya pihak akademi sangat terbantu dengan adanya kuesioner dari mahasiswa/i untuk mengetahui apa saja yang menjadi kekurangan di dalam akademi itu sendiri. Dengan dasar itu STMIK Indonesia Banjarmasin menyelenggarakan kuesioner tentang peningkatan kualitas dan kuantitas yang dinilai dari pandangan mahasiswa/i yang selama ini dirasakan.

Di STMIK Indonesia Banjarmasin kuesioner diselenggarakan oleh bagian BPMI (Badan Penjamin Mutu Internal) yang dilaksanakan sebelum periode bimbingan berakhir atau sebelum semester perkuliahan berakhir. Proses pelaksaannya pertama-tama dengan membagikan kepada mahasiswa/i kuesioner berupa media kertas yang nantinya disitu berisikan tentang pertanyaan-pertanyaan terhadap dosen, fasilitas ruangan proses belajar selama satu semester terakhir, lalu setelah selesai datanya dikumpulkan dan setelah dikumpulkan data tersebut di olah atau di

Jurnal IImiah "Technologia" 
presentasikan di masing-masing pernyataan sehingga bisa menghasil data-data tersebut.

Untuk proses pengolahan data kuesionernya, di STMIK Indonesia Banjarmasin proses perhitungan bobot kuesionernya menggunakan aplikasi Microsoft Excel dengan cara memasukkan data satu-persatu dari hasil kuesioner yang telah diisi oleh responden yang dalam hal ini yaitu mahasiswa/i STMIK Indonesia Banjarmasin. dengan cara seperti itu ada beberapa masalah yang muncul, salah satunya lambatnya proses untuk pengolahan datanya karena harus menunggu data kuesioner dimasukkan.

Berdasarkan latar belakang tersebut, sangatlah tepat jika STMIK Indonesia Banjarmasin menggunakan sisi kemajuan komputer baik piranti lunak maupun perangkat kerasnya dalam upaya membantu staf dalam upaya penanganan manajemen yang sebelumnya dilakukan secara manual. Dengan mempelajari masalah yang ada maka skripsi ini diambil judul "APLIKASI REKAPITULASI KUESIONER HASIL PROSES BELAJAR MENGAJAR PADA STMIK INDONESIA MENGGUNAKAN JAVA"

\section{RUMUSAN MASALAH}

Berdasarkan latar belakang di atas maka permasalahan yang akan di angkat dalam skripsi ini adalah: "Bagaimana merancang program rekapitulasi kuesioner hasil proses belajar mengajar pada STMIK Indonesia Banjarmasin sehingga hasil kuesioner bisa didapatkan lebih cepat?".

\section{METODE PENELITIAN}

\section{Analisis Sistem}

Alur proses evaluasi terhadap kinerja dosen adalah pertama BPMI membuat kuesioner yang berisikan evaluasi terhadap kinerja dosen, setelah itu kuesioner tersebut disebarkan atau dibagikan kepada masing-masing dosen saat melakukan perkuliahan untuk dibagikan lagi kepada mahasiswa buat melakukan penilain.
Setelah mahasiswa selesai memberikan evaluasi melalui kuesioner yang dibagikan tadi, kuesioner tersebut diserahkan kembali ke dosen yang bersangkutan untuk diserahkan kembali ke BPMI. Kemudian BPMI memproses dan mengolah data atau merekapitulasi kuesioner yang sudah mahasiswa isikan tadi sehingga akan menghasilkan tujuan dari kuesioner tersebut yaitu untuk evaluasi terhadap kinerja dosen STMIK Indonesia Banjarmasin. Untuk lebih jelasnya tentang alur proses kuesioner di STMIK Indonesia Banjarmasin bisa dilihat pada gambar dibawah ini

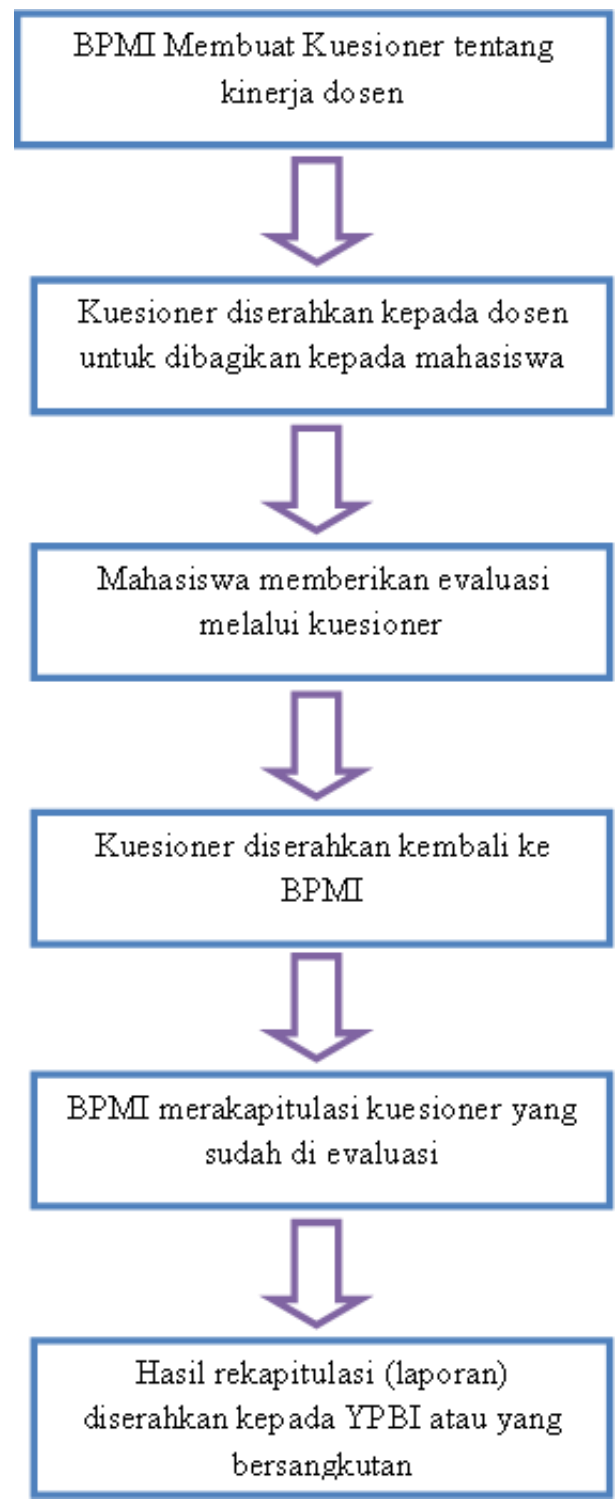

Gambar 1. Alur Proses Kuesioner STMIK Indonesia Banjarmasin 


\section{Metode Yang Diusulkan}

Untuk proses perhitungan data kuesioner digunakan metode Skala Likert. Sedangkan untuk pembuatan aplikasi menggunakan Bahasa pemrograman Java dengan aplikasi Netbeans 8.0 dan untuk penyimpanan data aplikasi menggunakan database MySQL.

\section{Skala Likert}

Skala Likert adalah suatu skala psikometrik yang umum digunakan dalam kuesioner dan merupakan skala yang paling banyak digunakan dalam riset berupa survei. Nama skala ini diambil dari nama Rensis Likert, yang menerbitkan suatu laporan yang menjelaskan penggunaannya. Ada dua bentuk pertanyaan yang menggunakan Likert yaitu pertanyaan positif untuk mengukur minat positif, dan bentuk pertanyaan negatif untuk mengukur minat negatif. Pertanyaan positif diberi skor 4, 3, 2, dan 1. Sedangkan bentuk pertanyaan negatif diberi skor 1, 2, 3, 4. Bentuk jawaban skala Likert terdiri dari sangat setuju, setuju, tidak setuju, dan sangat tidak.

\section{Perhitungan Skala Likert}

Untuk memperoleh hasil dari kuesioner dilakukan perhitungan hasil jawaban respoden dengan menggunakan metode Skala Likert.
Proses perhitungan Skala Likert dapat digunakan dengan langkah-langkah berikut ini.

a. Menentukan skor maksimal, yaitu skor jawaban terbesar di kali banyak item (soal).

b. Menentukan skor minimal, yaitu skor jawaban terkecil dikali banyak item (soal).

c. Menentukan nilai median, yaitu hasil penjumlahan skor maksimal dengan skor minimal dibagi dua.

d. Menentukan nilai kuartil 1, yaitu hasil penjumlahan skor minimal dengan median dibagi dua.

e. Menentukan nilai kuartil 3, yaitu hasil penjumlahan skor maksimal dengan median dibagi dua.

f. Buatlah skala yang menggambarkan skor minimal, nilai kuartil 1, median, kuartil 3 dan skor maksimal.

g. Carilah batas-batas skor untuk masingmasing kategori sikap.

h. Buatlah tabel distribusi frekuensi sikap tiap responden.

\section{Diagram Konteks \& DFD Level 0}

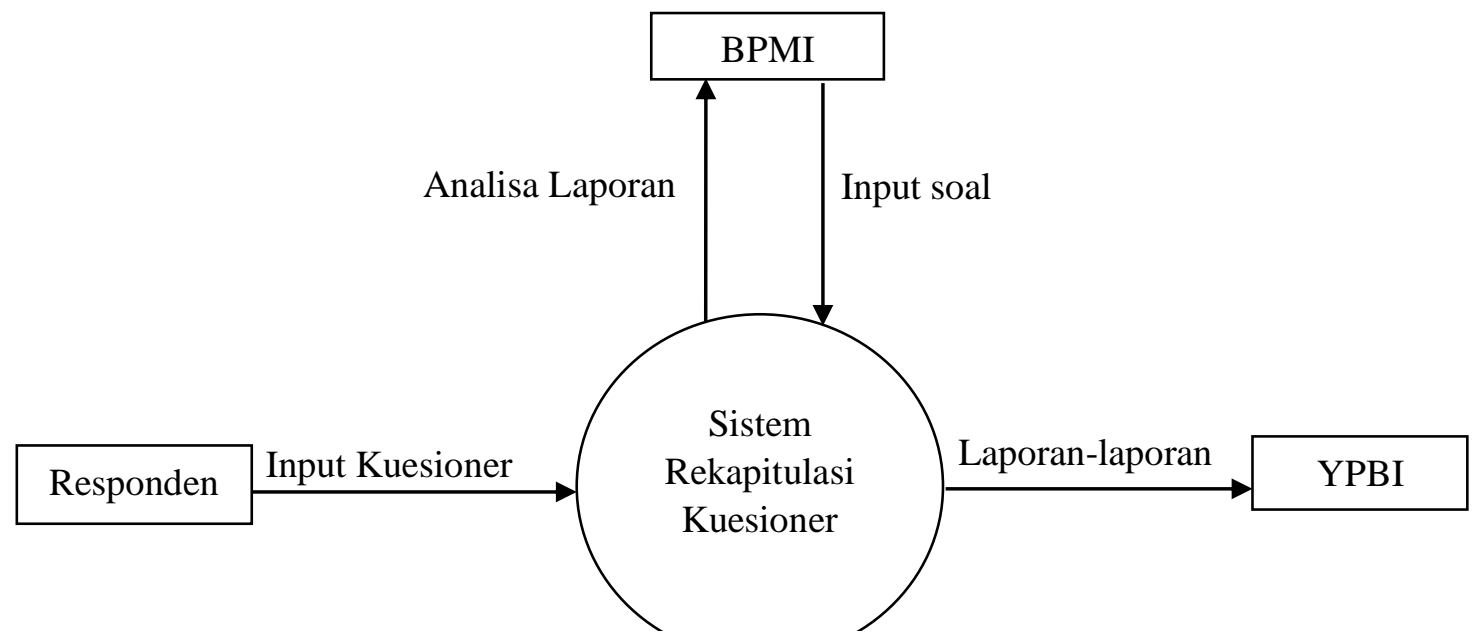

Gambar 2. Diagram Konteks 


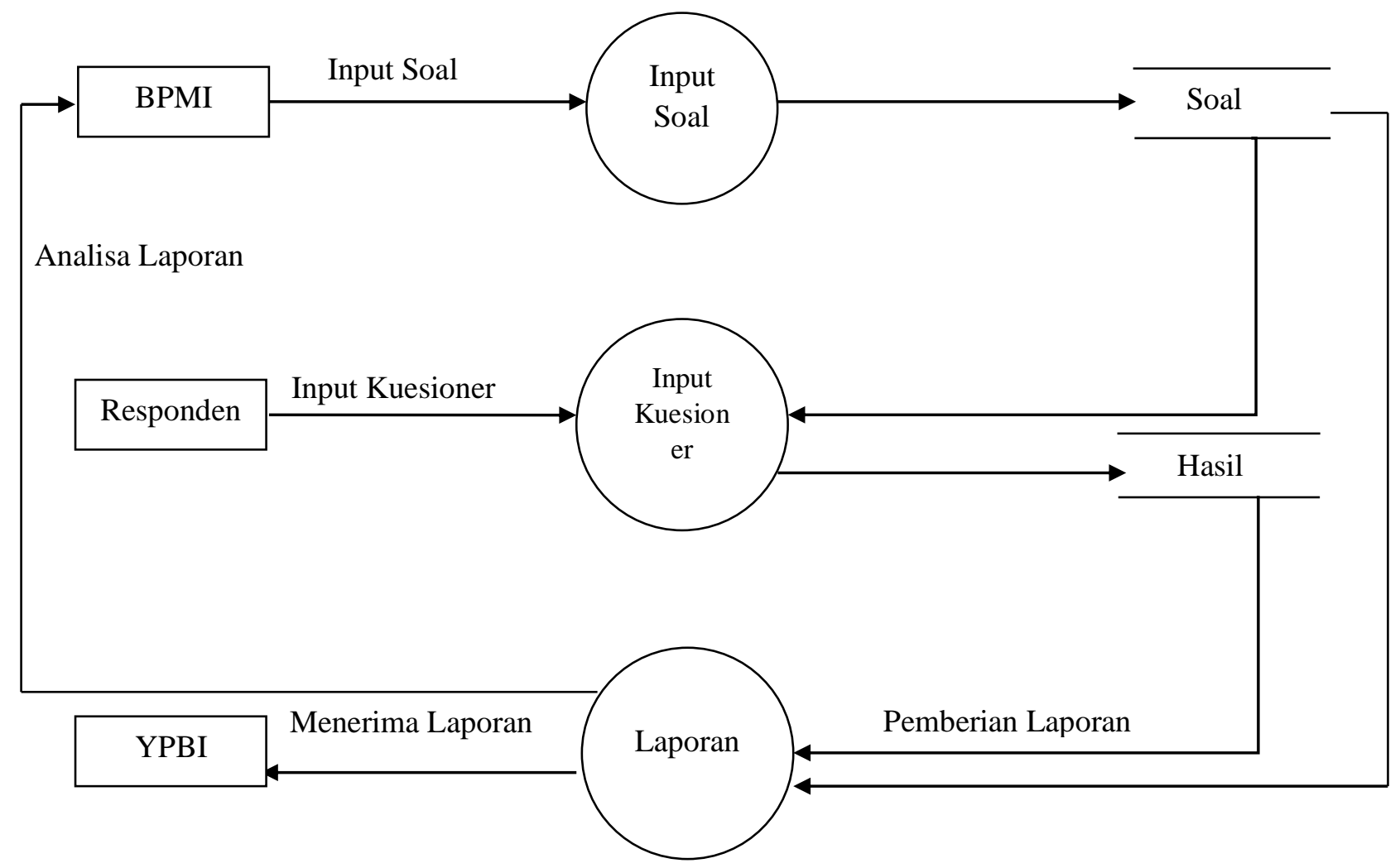

Gambar 3. Data Flow Diagram Level 0

\section{HASIL DAN PEMBAHASAN}

Aplikasi ini adalah aplikasi untuk merekapitulasi hasil data kuesioner proses belajar mengajar di STMIK Indonesia Banjarmasin untuk membantu dan mengoptimalkan manajemen data di STMIK Indonesia Banjarmasin. Dalam tampilan aplikasi ini dirancang semudah mungkin dalam hal penggunaan dan semenarik mungkin.

a. Form Login

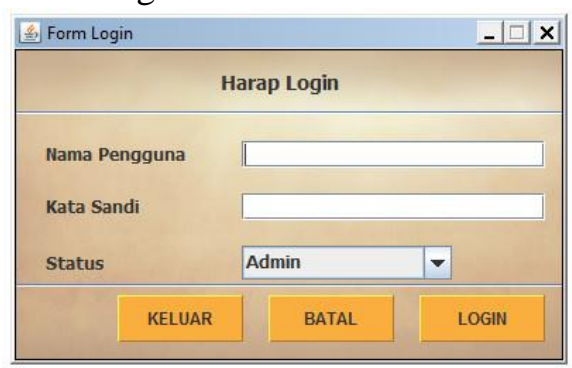

Gambar 4. Form Login

b. Form Utama
Aplikasi utama adalah form utama untuk aplikasi rekapitulasi kuesioner yang bisa dijalankan kalau login berhasil.

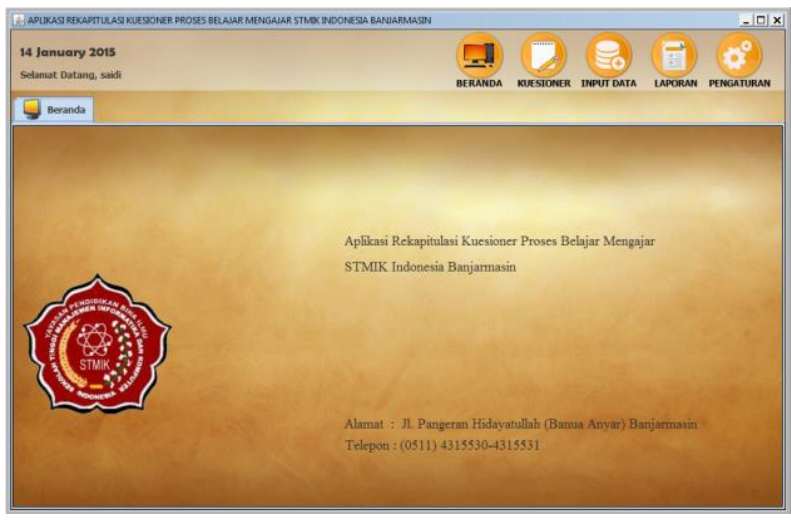

Gambar 5. Form Utama Aplikasi

c. Form Input Kuesioner

Di form inilah data hasil kuesioner mahasiswa di inputkan. Untuk menginputkan data kuesioner ke aplikasi, diisi terlebih dahulu nama mata kuliah dan dosen yang di evaluasi. Setelah itu baru penilaian mahasiswa di 
inputkan. Desain form input kuesioner adalah sebagai berikut:

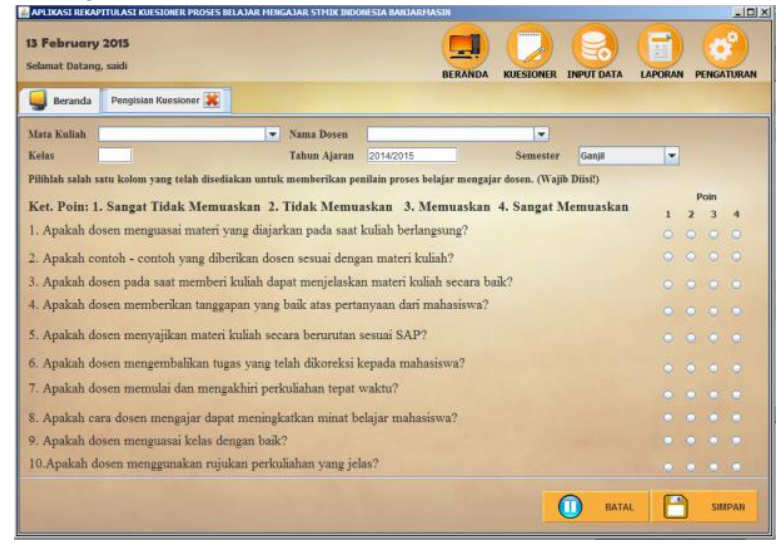

Gambar 6. Form Input Kuesioner

\section{d. Form Perbaharui Soal Kuesioner}

Di form ini apabila soal kuesioner ingin diperbaharui, maka di form perbaharui inilah tempatnya. Selain itu, data soal kuesioner juga ditampilkan pada form ini. Cara untuk memperbaharui soal kuesioner, pertama pilih dulu soal kuesioner yang ingin diperbaharui pada combobox pilih soal, kemudian di textfield soal langsung saja diperbaharui, setelah itu klik tombol perbaharui data. Kalau tidak ada masalah, maka akan muncul kotak pesan kalau data soal berhasil diperbaharui. Desain form perbaharui soal kuesioner adalah sebagai berikut:

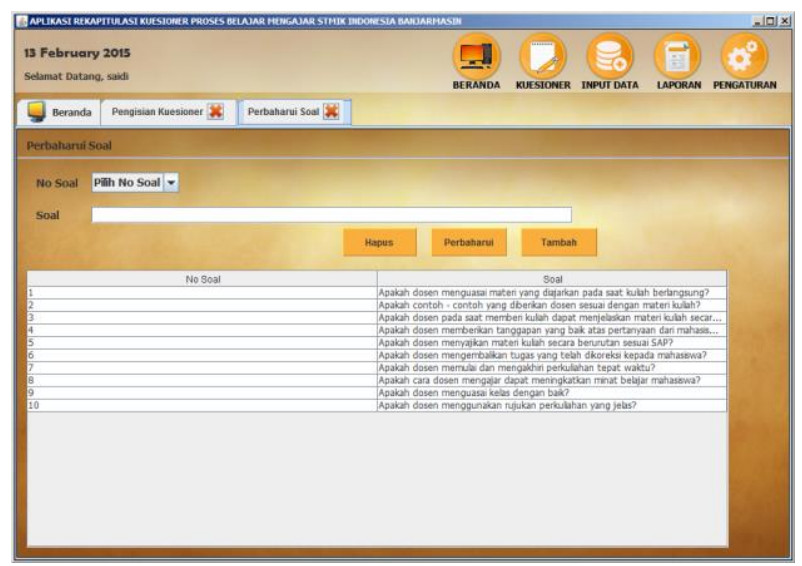

Gambar 7. Form Perbaharui Soal Kuesioner

e. Form Input Data Dosen

Di form ini digunakan untuk memanipulasi data dosen seperti menambahkan data dosen, memperbaharui data dosen dan menghapus data dosen. Untuk menggunakan fungsi manipulasi data dosen tersebut diharuskan login sebagai admin terlebih dahulu. Desain form Input Data Dosen adalah sebagai berikut:

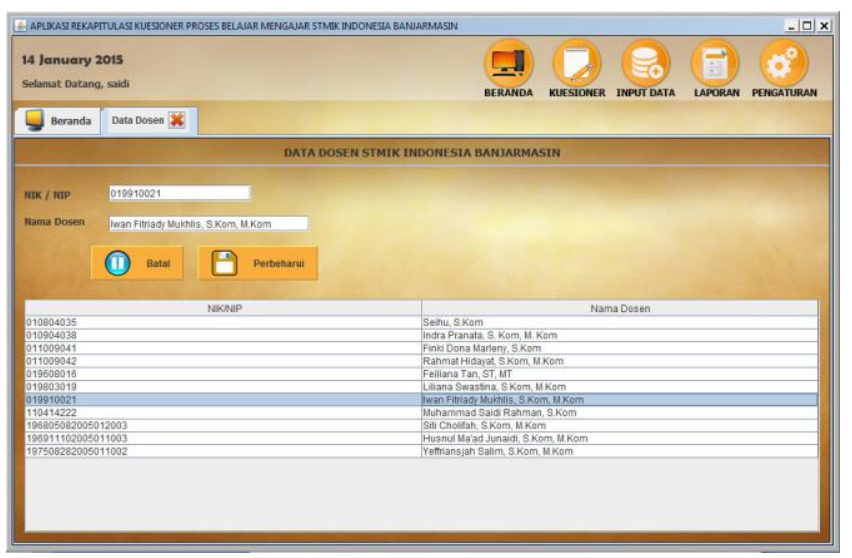

Gambar 8. Form Data Dosen

\section{f. Form Data Mata Kuliah}

Di form ini digunakan untuk memanipulasi data mata kuliah seperti menambahkan data mata kuliah, memperbaharui data mata kuliah dan menghapus data mata kuliah. Untuk menggunakan fungsi manipulasi data mata kuliah tersebut diharuskan login sebagai admin terlebih dahulu. Desain form Input Data Mata Kuliah adalah sebagai berikut:

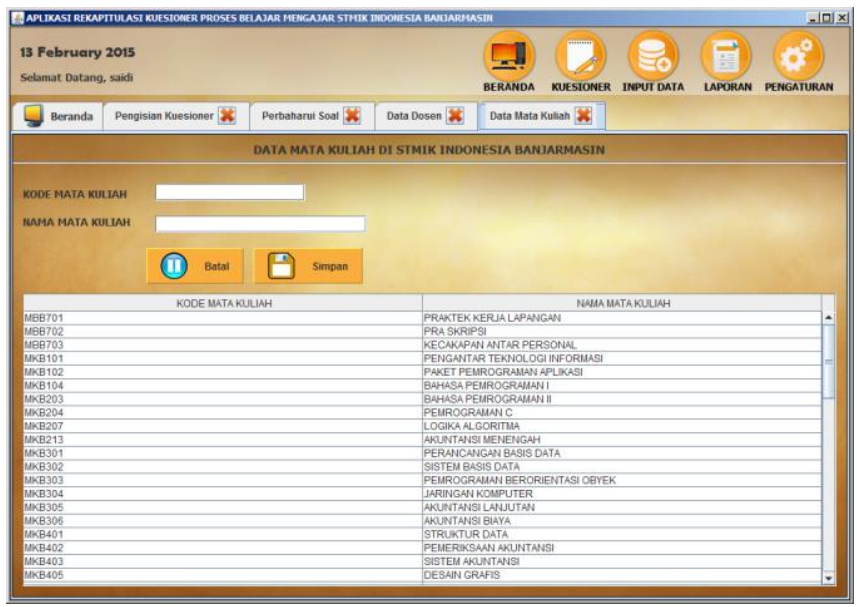

Gambar 9. Form Data Mata Kuliah

\section{g. Form Pengaturan}

Di form ini digunakan untuk mengganti sandi dari pengguna aplikasi ini. Untuk memperbaharui sandi masukkan sandi baru, 
sandi lama, konfirmasi sandi. Desain form Pengaturan adalah sebagai berikut:

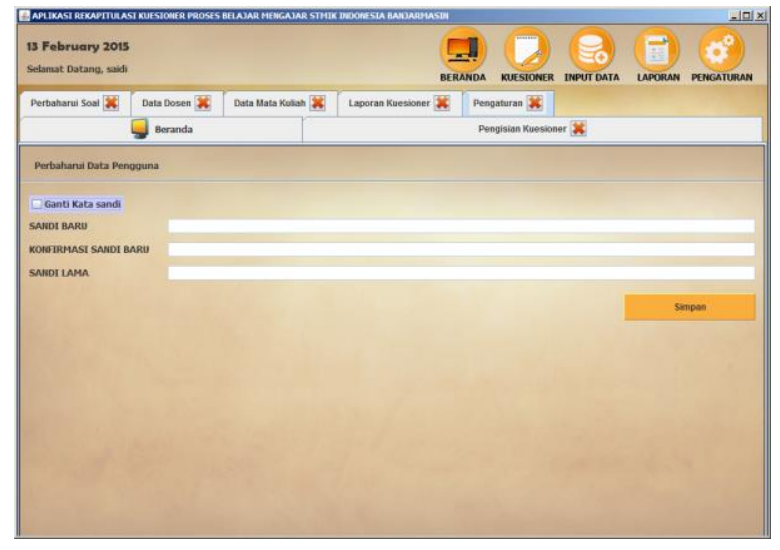

Gambar 10. Form Pengaturan Aplikasi

h. Form Laporan

Di form ini digunakan untuk mencetak atau memprint dari hasil input kuesioner yang sudah ditambahkan tadi. Untuk mencetak laporan kuesioner, pertama masukkan dulu mata kuliahnya, setelah mata kuliah di pilih, maka akan muncul daftar nama dosen yang mengambil mata kuliah tersebut. Kemudian nama dosen tersebut dipilih salah satu dan klik tombol cetak. Maka otomatis akan keluar laporan dengan mata kuliah dan nama dosen yang telah di input tadi. Desain interface Form Laporan adalah sebagai berikut:

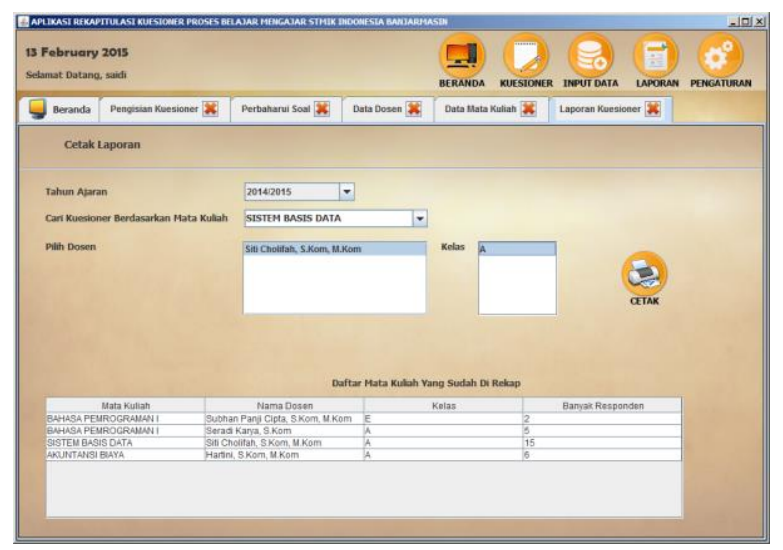

Gambar 11. Form Cetak Laporan

i. Laporan

Desain laporan rekapitulasi kuesioner hasil proses belajar mengajar pada STMIK Indonesia Banjarmasin adalah sebagai berikut.
Rekapitulasi Kuesioner Hasil Proses Belajar Mengajar Pada STMIK INDONESIA BANJARMASIN

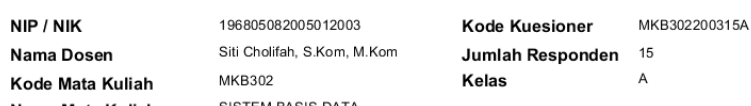

Nama Mata Kuliah

\begin{tabular}{|l|l|l|l|l|l|}
\hline \multirow{2}{*}{ No } & Pertanyaan & \multicolumn{3}{|c|}{ Skor Penilaian } \\
\cline { 3 - 7 } & $\mathbf{1}$ & $\mathbf{2}$ & $\mathbf{3}$ & $\mathbf{4}$ \\
\hline 1 & Apakah dosen menguasai materi yang diajarkan pada saat kuliah berlangsung? & 2 & 4 & 4 & 5 \\
\hline 2 & Apakah contoh - contoh yang diberikan dosen sesuai dengan materi kuliah? & 0 & 6 & 8 & 1 \\
\hline 3 & Apakah dosen pada saat memberi kuliah dapat menjelaskan materi kuliah & 1 & 2 & 6 & 6 \\
\hline 4 & Apakah dosen memberikan tanggapan yang baik atas pertanyaan dari & 0 & 3 & 0 & 12 \\
\hline 5 & Apakah dosen menyajikan materi kuliah secara berurutan sesuai SAP? & 0 & 4 & 7 & 4 \\
\hline 6 & Apakah dosen mengembalikan tugas yang telah dikoreksi kepada mahasiswa? & 1 & 2 & 8 & 4 \\
\hline 7 & Apakah dosen memulai dan mengakhiri perkuliahan tepat waktu? & 0 & 2 & 9 & 4 \\
\hline 8 & Apakah cara dosen mengajar dapat meningkatkan minat belajar mahasiswa? & 0 & 6 & 4 & 5 \\
\hline 9 & Apakah dosen menguasai kelas dengan baik? & 0 & 1 & 12 & 2 \\
\hline 10 & Apakah dosen menggunakan rujukan perkuliahan yang jelas? & 0 & 2 & 4 & 9 \\
\hline
\end{tabular}

Keterangan Skor

$1=$ Sangat Tidak Memuask

$3=$ Memuaskan

$3=$ Memuaskan
$4=$ = Sangat Meme

Kesimpulan:

Berdasarkan skor yang didapat seperti data diatas dan direkapitulasi menggunakan perhitungan Skala Likert hasilnya adalah Memuaskan

Gambar 12. Desain Laporan Hasil Kuesioner

\section{KESIMPULAN}

Dengan adanya aplikasi untuk rekapitulasi kuesioner hasil proses belajar mengajar ini diharapkan bisa membantu para staff Badan Penjamin Mutu Internal (BPMI) untuk melakukan rekapitulasi kuesioner dari hasil proses belajar mengajar dalam hal ini mahasiswa sebagai responden nya. Kemudian hasil rekapitulasi tadi bisa langsung dibuatkan laporannya dengan cepat dan akurat. Sehingga dari aplikasi ini dapat meningkatkan kualitas proses belajar mengajar di STMIK Indonesia Banjarmasin ini.

\section{SARAN}

Dalam pembuatan aplikasi rekapitulasi kuesioner proses belajar mengajar ini tentunya belum sepenuhnya sempurna, oleh karena ini penulis beharap kedepannya aplikasi ini bisa dikembangkan menjadi aplikasi berbasis web atau mobile karena aplikasi yang dibuat pada penelitian ini hanya berbasis desktop saja. 


\section{DAFTAR PUSTAKA}

[1] Abdurahman, Fazar. 2014, Rancang

Bangun Pengolahan Data Hasil Kuesioner Evaluasi Kinerja Dosen Pada STMIK Indonesia Banjarmasin Menggunakan Microsoft Visual Basic 6.0, Banjarmasin.

[2] Arikunto, Suharsimi. 2006. Metodelogi penelitian. Yogyakarta: Bina Aksara.

[3] Heryandi, Andri. 2012, Pembangunan Sistem Informasi Pengisian Survey Evaluasi Perkuliahan Online Di Universitas Komputer Indonesia.

[4] JENI (Java Education Network Indonesia). 2009. Pengenalan Bahasa Java

[5] Khannedy, Kurniawan, Eko. 2012, Pemrograman Database Menggunakan Java dan MySQL, Stripbandunk, Bandung.

[6] Nuraeni, Yeni. 2008, Perancangan Sistem Informasi Penjaminan Mutu Perguruan Tinggi Bidang Sumber Daya Manusia.

[7] STKIP YPM BANGKO. 2014, Skala Pengukuran Statistik Inferensial 